\title{
Review on the Key Features of the National Education Policy 2020 in the Context to Pre- school Education and its Expected Impact
}

\author{
Renu Gandhi \\ Assistant Professor (Selection Grade) \\ Department of Life Long Learning and Extension (DLLL\&E), Panjab University, \\ Chandigarh, 160014, India \\ ORCID code: 0000-0001-9040-1083, Email: renunidhigandhi@gmail.com
}

Area/Section: Education Management.

Type of the Paper: Review based Analysis.

Type of Review: Peer Reviewed as per $|\mathrm{C}| \mathrm{O}|\mathrm{P}| \mathrm{E} \mid$ guidance.

Indexed in: OpenAIRE.

DOI: https://doi.org/10.5281/zenodo.4992735

Google Scholar Citation: IJMTS

\section{How to Cite this Paper:}

Renu Gandhi, (2021). Review on the Key Features of the National Education Policy 2020 in the Context to Pre-school Education and its Expected Impact. International Journal of Management, Technology, and Social Sciences (IJMTS), 6(1), 241-252. DOI: https://doi.org/10.5281/zenodo.4992735.

International Journal of Management, Technology, and Social Sciences (IJMTS) A Refereed International Journal of Srinivas University, India.

CrossRef DOI: https://doi.org/10.47992/IJMTS.2581.6012.0143

(C) With Author.

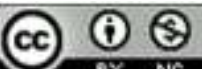

This work is licensed under a Creative Commons Attribution-Non-Commercial 4.0 International License subject to proper citation to the publication source of the work.

Disclaimer: The scholarly papers as reviewed and published by the Srinivas Publications (S.P.), India are the views and opinions of their respective authors and are not the views or opinions of the SP. The SP disclaims of any harm or loss caused due to the published content to any party.
\end{abstract}




\title{
Review on the Key Features of the National Education Policy 2020 in the Context to Pre-school Education and its Expected Impact
}

\author{
Renu Gandhi \\ Assistant Professor (Selection Grade) \\ Department of Life Long Learning and Extension (DLLL\&E), Panjab University, \\ Chandigarh, 160014, India \\ ORCID code: 0000-0001-9040-1083, Email id: renunidhigandhi@ gmail.com
}

\begin{abstract}
Purpose: The New Education Policy (NEP-2020) aimed to revitalize the early childhood care and education (ECCE) program as $\approx 85 \%$ of child's cumulative brain proliferation occurs prior to 6 years. This initiative is made with special emphasis for socio-economically disadvantaged background communities to ensure better paradigm development of each preschooler. It will allow each child to flourish in life and enhance its skills to give better output in the future and be a useful citizen for the nation. Current digital India and Atma Nirbhar Bharat make it imperative to revitalize each member of the community with mandatory basic skills. For instance, basic financial transactions, online job application forms, electricity bills, fee payments, home shopping, and many more. The pandemic situation has amended the turmoil among the community, which again necessitates basic learning among people. India had made a remarkable stride through initiatives like "Right to Education Act" and "Sarva Shiksha Abhiyan" to ensure the maximum spread of literacy across the nation. With the current unprecedented scenario, a spurring behavior needs to be established to identify key features of NEP-2020, its role, implication, future impact and role of various stakeholders associated. The Present review aims to understand an imperative approach of NEP-2020 towards preschooler's development and its significance for disadvantaged groups and non-literate members of the community.
\end{abstract}

Design: Identifying the significance of preschool education programs and implementation strategies proposed by NEP 2020.

Originality/ Value: The positive impact of NEP-2020 in the development of foundation skills of preschoolers and spread of ECCE program to each section of community to ensure well development of preschooler's stage.

Paper type: Review based Analysis.

Keywords: National education policy; preschool education; community; literacy; education.

\section{INTRODUCTION :}

Origin of National Education policy (NEP-2020) lies in the schematic $5+3+3+4$ paradigm approach as depicted in Fig. 1 highlighting imperative asset of preschooler's development for building block of education and its efficacy [1]. It aims to contribute significantly in the fourth Sustainable development goal (SDG) of imparting quality education to all the citizens belonging to each section of the community. Tierney et al. [2] has reported the significance of prenatal period for the early brain development, which spurs the requirement of an appropriate planned education system during early childhood care. Moreover, NEP has categorically mentioned that $85 \%$ child brain development at prenatal stage requires mandate awareness to a child to develop necessary skills, habits and basic etiquettes before 6 years. The fundamental right to education act 2009 helped in spreading literacy across the nation. However, play way and preschool learning was missing in under developed community due to its optional implementation and lack of access by underprivileged people [3]. Preschool age corresponds to pre-formal learning stage preparing a child to understand the education system and develop necessary skills to acquire a paradigm education system [4]. It has been reported in literature that students having preschool learning experience have better efficacy in learning in comparison to the students without 
any early childhood education program experience [5-7]. NEP 2020 lays emphasis on four basic key reform areas: qualitative learning amendment in all levels of education, curriculum modification to enhance foundation skills, following alterative assessment analysis and schematic paradigm transformation. As illustrated in Fig. 1, the Foundation stage corresponds to non-formal mode of education, in which during first 3 years (in 3 to 6 years of his/her age) a child will enter preschool stage through proper play way/ preschool school inculcating play-way activities, focus on basic etiquettes, team work, gestures, sharing, cooperation, hygienic practices to be followed. In current education system also, parents prefer to send their children to play-way, Montessori school or other play way activity training centers, but it is an optional mode with no mandate. Moreover, during past, lack of access to preschools by underprivileged parents and choosing suitable quality preschool were major challenges. With introduction of this novel NEP 2020 foundation stage, it will become a mandate feature to provide amenable infrastructure to children belonging to poor families to amend their early childhood skills. Similar to the case of right to education act, 2009, this 3 year of foundation stage will provide the right platform to the preschoolers belonging to each section of the society to elicit their skills to compete with other children in alike manner in their preparatory stage. The Grade 1 and Grade 2 of the foundation stage inculcate learning basic mathematical skills, sciences, number counting, etc. through fun and play activities in an informal paradigm approach. Basically, these 2 years of foundation stage aims up in establishing building blocks of a child to enable him to make dissents in its formal learning stages in Preparatory module. Practical activity demonstration tools will be utilized by the trainers during Preparatory stage to educate basic scientific skills to the learners and developing their basic mathematical concepts. Learning will be made fun, interesting, informative and innovative. Light books with interactive teaching skills will be followed in preparatory module to prepare a child for formal education system in the middle stage.

Middle stage corresponds to the formal learning and teaching stage for the students with three years appropriate infrastructure and syllabus curriculum. This stage inculcates subject teachers to teach subject wise curriculum as in the current education system. In this mode, a child has been well trained and planned to undertake formal training and capture advanced teaching skills. The novelty of NEP 2020 is to correlate the significance of each subject to practical implementation while enhancing knowledge skills of the students through experimental learning. High school inculcates four years programs with compulsory first two grades and optional last two grades. It obviates the bridge between arts and science, creativity and critical thinking and curriculum and extra curriculum activities. This high school module provides flexibility to the students to prioritize their programs and learning trajectories.

\section{OBJECTIVES OF THE PAPER :}

The present review aims to highlight an innovative approach proposed by NEP 2020 to emphasize enhancement in learning skills and training methodology for preschoolers enabling appropriate early childhood care and development. The key features highlighted in the paper include:

(i) Role of policies and recommendations of NEP 2020 imperative for spurring pre-natal learning among toddlers.

(ii) Sensitization of age savvy and language savvy teaching skills required for effective communication with preschoolers through NEP 2020.

(iii) Significance of a preschool infrastructure, trained and qualified teachers to guide, monitor and supervise early childhood education program.

(iv) Compiling teaching methodology, demonstration tools recruiting high quality teachers and study material for preschoolers training program as suggested by NEP 2020 .

(v) To provide suggestions for the implementation part of NEP 2020 in context to preschool education and its expected impact.

\section{METHODOLOGY \& DATA :}

Systematic review and Meta analysis of NEP 2020 with respect to preschool education program and its implementation approaches is conducted to analyze its expected impact. The data inculcates the positive impacts of introducing preschool education program as a mandatory protocol in NEP 2020 while citing the reports and studied of researchers explaining the significance of early childhood education at an early stage. 


\section{REVIEW OF RELATED RESEARCH :}

NEP 2020 replaces the thirty four year old National Policy on Education (NPE 1968) by substituting $10+2$ structure of school curriculum with $5+3+3+4$ structure emphasizing on Early Childhood Care and Education (ECCE) [8-11]. The uncovered age group of 3-6 years in NPE is inculcated as mandatory education pedagogy in NEP 2020 to develop pre-natal age of children belonging to each section of the society. Especially undeveloped and poor section of the society is aimed to be covered under this innovative policy $[10,11]$. Aithal et al. $[10,11]$ has reported a detail review on analysis of the objectives and implementation of NEP 2020 in higher education system and in achievement of fourth SDG. Belsky et al. [12] has highlighted the significance of developmental risks associated with early child care, which suggests efficacy of NEP 2020 in determining growth and development parameters of preschoolers in early stages. Tilak et al. [13] has reported a critique of the NEP 2019 draft and analyzed the policy gaps and unacceptable facts regarding long term education methodology and impact on each stage. Maruthavanan et al. [14] has reported a case study on sensitization and awareness about draft NEP 2019 among secondary school government, self -financed and aided teachers of Madurai district. Twentyfive parameters were chosen for the survey based on population, location, gender, years of service, management strategies and family background. They have observed that male teachers had more awareness about NEP 2019 draft policy as compared to female teachers [14]. Similarly urban school teachers and teachers working in government schools reported better awareness in comparison to rural and self-finance teachers, respectively [14]. Teachers belonging to joint family reported better awareness as compared to nuclear families on account of more probability of interaction and sharing views with each other [14]. Kalyani et al. [15] has reported the effect of four challenges of NEP 2020 namely quality, equity, affordability, accountability and access on the associated stakeholders (students, teachers and parents). According to NEP 2020, minimum eligibility for recruitment of government teachers will be four-year B.Ed. degree and Teachers Eligibility Test (TET) certificate $[1,15]$. This will allow recruitment of high-quality staff for amending efficacy of preschool learning program [15]. Pianta et al. [16] reported the role of public policies and evidence based approaches on the effect of preschool education. The evidence studies were conducted from head start, public school and child care programs utilizing research and experimental methods. A long-lasting positive impact of preschool program was reported on young children's social and cognitive development both experimentally and research study. Minor evidences suggested negative impact on social behavior of preschoolers but were not confirmed experimentally [16]. Devi et al. [17] and Jha et al. [18] have reported the awareness of the stakeholders of management and commerce discipline on NEP 2020 and have appreciated the dominance of practical methodology of training skills in current NEP 2020 policy in comparison to theoretical study approach practiced in the past $[17,18]$. They have concluded about the need to reframe the curriculum of management and commerce in paradigm manner based on outcome based education [17]. A prior awareness to stakeholders is required before implementation process of a particular program to enhance efficacy of the program $[17,18]$. Sawant et al. [19] justified the primary education, numeracy outcomes and poor literacy as thrust areas of NEP 2020 due to evidence based reports of lacking basic numeracy skills among $50 \%$ children even after 5 years learning in school in the current education system [19]. Kaurav et al. [20] has identified three critical aspects of NEP 2020 namely; students, language and course and reported positive aspects and opinions of the stakeholders towards NEP 2020. The three different aspects of NEP of India are (i) concerns regarding education, research, institution and students, (ii) Anecdotes inculcating policy, teaching, integrity, enable, innovation and knowledge and (iii) Focus constituting quality, development, university, vocational, learning and multidisciplinary [20]. Manhas et al. [21] has explained the differences in teaching skills of Anganwadi workers and preschool teachers from four districts of Kashmir division while taking 60 sample size of each category. The parameters taken for the study were: provision of basic amenities and books, development activities, methodology and tools to demonstrate teaching skills to preschoolers, infrastructure inculcating building and rooms [21]. Better results were found to be for preschools due to better infrastructure and well equipped facilities in comparison to Anganwadi centres [21]. 


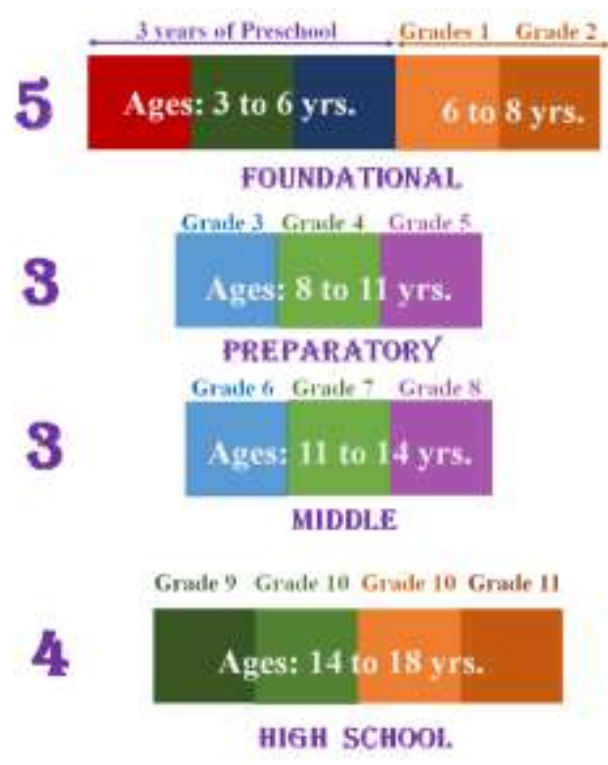

Fig. 1: Schematic illustration of the pedagogy for the NPE-2020

\section{ROLE OF EDUCATIONAL INSTITUTES AND TEACHERS TOWARDS NEP 2020 AND ITS IMPLICATION :}

NEP 2020 aims to imbibe moral values and traditional knowledge in children with spurring exposure towards versatile computational skills, design thinking, coding, digital literacy, ethical reasoning, etc. $[1,9]$. Aithal et al. $[10,11]$ has reported early streaming of students in different disciples as one of the major reasons for the fragmentation of secondary education system of India. Therefore, emphasis on early childhood education by NEP 2020 articulates the notion behind this idea to obviate an austerity in the current education system. Moreover, it has been analyzed a significant amendment in number of school dropouts in higher classes (11\%) in comparison to $75 \%$ of the children in the age group of 6 to 16 years attending the schools [13]. In addition to financial issues, family status, caste and regional issues, absence of innovative learning environment by educational institute's clientele towards dwindling students' interest in education [11-25]. Chopra et al. [26] has reported a qualitative study on the environment, platform, apex body, monitoring committee and infrastructure of early childhood education programs. Five different categories of pre-schools chosen for the study are depicted in Fig. 2.

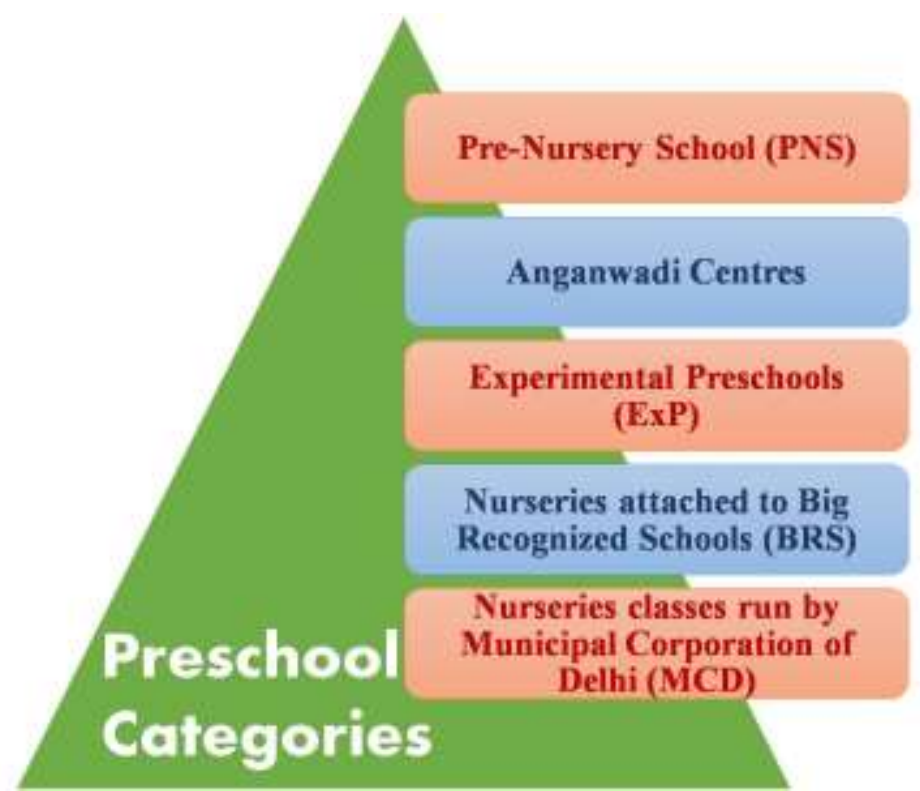

Fig. 2: Different categories of preschools 
Pre-Nursery School (PNS), which may run privately and does not require any recognition nor accreditation, Anganwadi centres under the Integrated Child Development Scheme (ICDS), Ministry of Human Resource Development, Experimental Preschools (ExP) run for experimental studies by Child Development or Education departments of different universities, Nurseries attached to 'Big Recognized School (BRS), which are recognized and have well established model to enroll students from nursery to $12^{\text {th }}$ standard and Nursery classes of schools run by Municipal Corporation of Delhi (MCD) were selected for the study [26]. ECCE trained teachers from a recognized institute were one of the major parameters determining the quality of an educational institute. It was reported that $100 \%$ of the recruited trainers were ECCE trained teachers in ExP and more than $75 \%$ in BRS [26]. However, in PNS, $60 \%$ of the teachers were not ECCE trained but the educational status of mothers of preschoolers belonging to PNS was literate and efficient infrastructure of PNS managed to obviate this limitation. The Tamil Nadu Early Childhood Environment Rating Scale (TECERS) with a consortium of seven components namely; social development, fine and gross motor skills, creative activities, personal care and routine, language and reasoning, physical learning aids and infrastructure can be utilized for assessing quality of a preschool [26-28]. Chopra et al. [26] had reported best infrastructure by ExP by following a developmental approach and principles of child development while preparing the curriculum unlike BRS and PNS following academic approach focusing on learning of 3 R's in the system. An imperative role of a regulatory model accrediting and providing license to preschooler programs while appropriate impact assessment can't be ignored [29]. This is because for implementation part of a particular project, a stringent supervision and monitoring is mandatory [2932]. Balance between the quality of care, education, cooperation and support from home and child care centre will also play a vital role in effective functioning and implementation of NEP-2020 aims and objectives for preschooler's development [33]. Yizengaw et al. [29] has reported variations in curriculum implementation between private and public preschools and signified the role of policies, incentives for teachers and other staff, infrastructure and supervision by the government authorities as a contributing factor for implementation mechanism.

The aim of NEP-2020 to recognize and foster unique amenabilities of each preschool initiates with sensitizing parents and teachers to promote each student holistic development in both academic and non-academic phases [34]. The role of teachers and educational institutes is to create platform for conceptual learning, rather than rote learning and exams preparation. The demonstration and practice tools utilized during training sessions with the children should be age friendly as per the preschool stage and grade level of a child. Teachers and faculty of an ECCE program are heart of learning for the students and should provide a niche environment with positive working environment, hygienic and service conditions. A light but tight regulatory module should be maintained to ensure articulation, resource efficacy, innovation practices and integrity of an education program. This allows establishment of appropriate decorum of maintaining the requisite environment for the preschoolers.

\section{SIGNIFICANCE OF EXPERIENTIAL LEARNING IN PRESCHOOLER'S DEVELOPMENT :}

Experiential learning inculcates exploring inter-relations among different subjects, sports and arts integrated education, storytelling and hands-on learning, and activity demonstrations paradigm pedagogy. It not only allows fun-based learning mechanism, but also spreads traditional, moral and patriotic knowledge to pre-learners [35].

\subsection{Arts and sports integrated education}

This education system utilizes versatile aspects of arts and culture which also helps in imbibing Indian ethos in children during learning process. Organization of incentivizing drawing, fancy dress and other art and craft competitions helps them in understanding the significance of Indian festivals, patriotism, Indian culture, Indian freedom fighters and other culture and moral values. Similarly, sports education through physical activities, age savvy games and demonstrating animated sports videos emphasize development of physical health, cooperation, sharing, team work, patience, struggle, handling defeat and victory and other cognitive amenabilities among children.

\subsection{Power of language and Multilingualism}


A novelty in NEP-2020 is initiation of giving significance to mother language for the mode of communication to learning and education till grade 5 (Fig. 1). Mudzielwana et al. [36] and Saracho et al. [37] have made an assessment on the effect of language as a mode of instruction utilized in preschools. They have mentioned about the challenges and risks teachers should be ready to take and well-trained to handle the group of children belonging to different linguistic backgrounds [36, 37]. This is because, as per the policy recommendation and reported studies [38-40], children are more comfortable in learning through their mother language during initial stages (3 to 6 years), in which they need to develop their knowledge skills with efficacy to evolve better preparatory for higher education system [38-40]. To overcome, this challenge, bilateral agreement between different states of India to hire teachers in large numbers with varied language skills is recommended [1,9]. In addition, extensive utilization of technology for learning and teaching different regional languages is also recommended. Basically NEP 2020 also promotes language learning as part of children's training pedagogy [1]. Therefore, to enhance the learning amenabilities of children they are expected to be more prone through friendly language (mother language) and other linguistic languages which will help them to understand things quickly and enhance their communication skills in all regions of the community [40]. It will also help in development of social skills of children and promote national unity [1, 41]. However, for the implementation process, concrete efforts will be required for compiling high quality textbooks in bilinguistic languages and other teaching study materials in learner's friendly language. The threelanguage formula will continue to be implemented, while considering constitutional provisions, aspirations of the people belonging to different regions, religions, community and as per the flexibility of the preschool learner $[1,9]$. An initiative "Ek Bharat Shrestha Bharat" as a fun cum learning project is also proposed for the children under language development scheme program in Grades 6-8 (Fig. 1). This project aims to make children learn about the various geographical areas, tribal structures and different languages they speak and use for communication.

\section{DEVELOPMENT OF BASIC SKILLS, HABITS AND PERSONAL HYGIENE CONDITIONS AMONG PRESCHOOLERS :}

The main highlight of inculcating preschool education system in $5+3+3+4$ structure (Fig. 1) lies in the development of basic skills among toddlers, which are significant for making them a better citizen in future. This is because these elementary basic skills foster grass root development of a child in foundation skills, which makes him a responsible person with amenable skills to move in the society [42-44]. In early education programs, there is more emphasis on oral language development for interactions, friendships and social relationships with inmates [44].

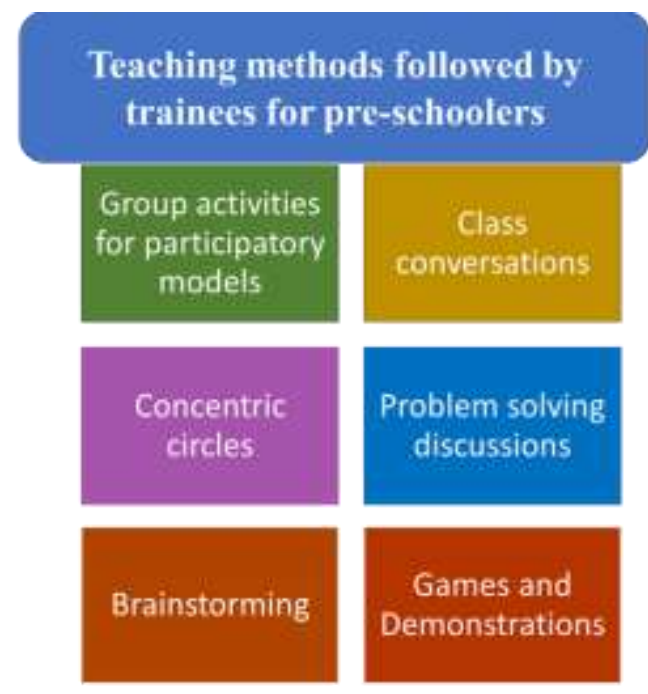

Fig. 3: Different methods for training basic and hygienic skills to preschoolers

Washing hands as one of the key factors of personal hygiene has become indispensable habit to maintain not only by preschoolers but by all individuals in this current pandemic scenario. A. L. Bashtawy et al. [45] has highlighted teaching personal hygienic practices to preschoolers as a best tool to amend 
community strategies to handle many communicable and pandemic diseases. It's an imperative practice to teach these skills to children at an early age in the current pandemic scenario [32, 46]. Obeng et al. [47] has reported pilot study of 58 preschools incorporating 112 preschool teachers as stakeholders and found that $32 \%$ of the teachers gave preference to teach hand washing practices to the toddlers. Other activities on discussion of germs, mouth covering during coughing and sneezing, glitter, proper dental care and appropriate use of washroom from time to time were given preference by $20 \%, 16 \%, 9 \%, 7$ $\%$ and $4 \%$, preschool teachers respectively among the selected teachers. Glitters, sparkles, use of poster colors, water colors, gums, paper folding colored papers and other origami products utilized during play way activities may cause infections to other children if not washed properly. In the current pandemic scenario, teachers should be well trained and equipped with all the necessary modules and protocols to maintain proper clean decorum during preschool teaching, guide, supervise and monitor the same among children during play activities. Therefore, as per the current pandemic scenario [31], initiation of NEP 2020 in beginning age of children (3-6 years) becomes a substantive task to be followed. Proper teachers should be recruited and should be well trained and monitored from time to time. Kerich et al. [48] has explained the various teaching methods utilized by the teachers to facilitate hygienic practices and other basic skills among preschoolers. They are illustrated in Fig. 3.

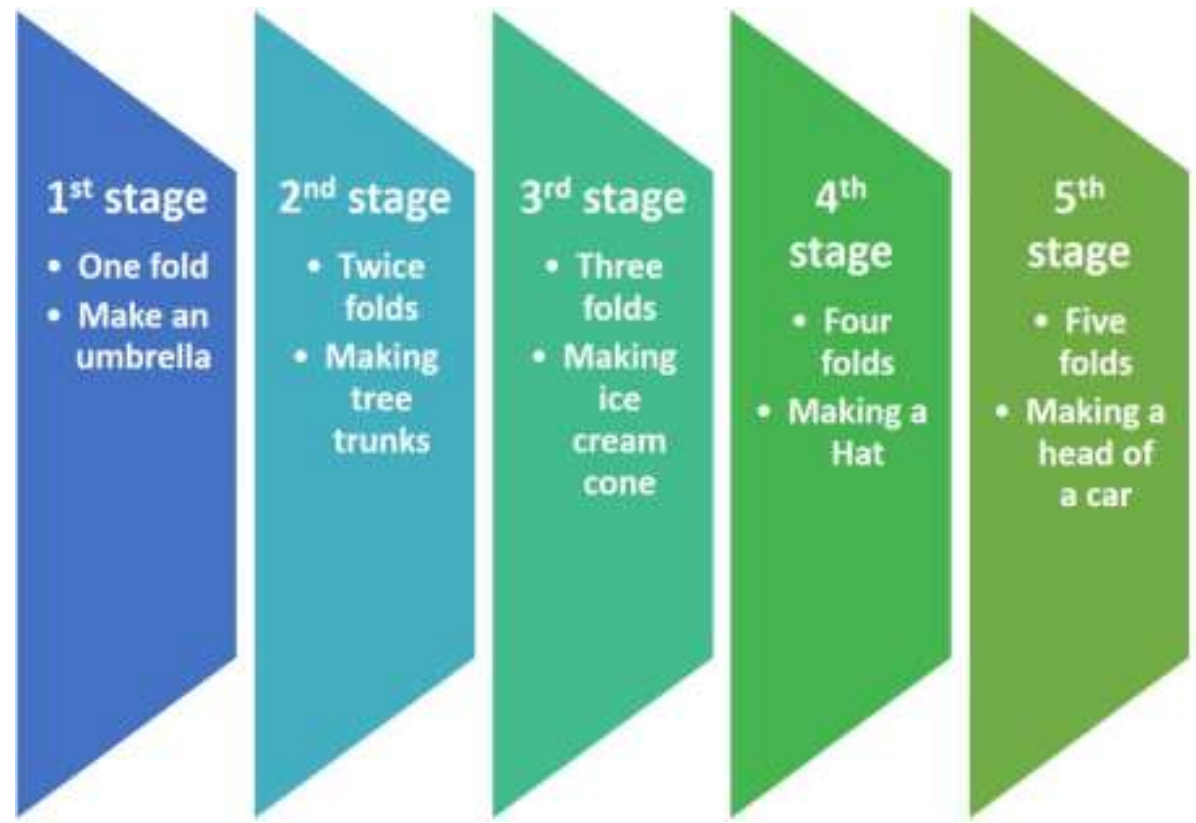

Fig. 4: Five stages of folding activities

Group activities for participatory models are an imperative approach for social development of preschoolers. Cooperation, patience, exchange of opinion, sharing things, discover new things, creative expressions, team work, etc. are some of the skills inculcated during group activities among toddlers. Both small group and large group activities including indoor and outdoor play helps a child to interact with other children of different views, nature, understanding and hence socially active. A preschool is the first stage where a child moves out of his/her niche environment of home and face the society. Therefore, early training of a child (before 6 years) helps to develop his social and interactive skills which train his/her as responsible person with appropriate etiquettes to move in a society. Moreover, it becomes responsibility of a trainee or a preschool instructor to nurture trust in the group while monitoring, supervising and guiding each child at each stage of group activity. Small group discussions should preferably in concentric circles which make possibility of students facing each other and hence better mode of interaction [47]. The inner and outer circle students can discuss easily in pairs and then feedback and sharing of views can be done with other groups. This will help preschoolers to share their ideas and develop friendly attitude with inmates. Small poetry rhymes and problem-solving discussions (depending on the age group 3-6 years) should be facilitated through story telling programs. For example, after narrating the story, students can be asked about moral of the story, problem behind the story and many mother questions to imbibe moral values in them. 
In addition, colorful activities, coloring, painting, paper folding and other origami activities helps in amending fine motor skills of preschoolers [49]. Widayati et al. [50] has demonstrated a study on the enhancement in fine motor skills as well as learning geometry, shapes and sizes through paper folding activities of preschoolers. They had utilized five stages of folding as depicted in Fig. 4 to explain the role of teachers in demonstrating origami activities to preschoolers. To teach folding steps to kindergarten, folding steps should be thorough with the teachers, as it requires visual spatial abilities, hand skills and proper eye coordination [50,51]. The various benefits of paper folding include; development of perfect motor skills in both the hands, amended creative power amenabilities, improves concentration, memory skills and patience to the learners. Step by step practice of paper folding activities by learners and guidance by the teachers help in proper development of their fine motor skills.

\section{SUGGESTIONS :}

(i) There is a need to introduce planning sessions for implementation of preschool education program.

(ii) Resources, facilities and appropriate assistance to be provided to the preschool teachers as per the requirement.

(iii) Early learning is different from higher education program. Preschoolers have curiosity, enthusiasm and anxiety; therefore, the preschool teachers recruited should be well trained qualitatively.

(iv) Preschool teachers should be well trained in guiding and handling preschoolers in developing empathy, following directions from preschoolers, team work and should have well expertise in local language.

(v) Concept of care as per ECCE full form is invisible in NEP 2020 and should be more elaborated and paid attention as child care in early stages is pre-requirement for his/her overall growth and development.

\section{CONCLUSIONS :}

NEP 2020 allows flexibility for the learners to select their learning programs and trajectories depending on their ability, passion and focus [52]. It obviates the barriers between curricular and extra-curricular activities, sciences and arts, academic and vocational to ensure integrating inputs of knowledge. Its special focus on early childhood care program at appropriate age groups of children (3 to 6 years) may prove it as a viable tool for student's proliferation. Development of personal hygiene skills for preschoolers is a mandatory training required in the current pandemic scenario and averts spurious infections or diseases in future. Creation of better infrastructure for preschoolers and recruiting high quality trained staff for training the learners will enable proper development of social, cognitive, life skills, equity and inclusion, constitutional, moral values and other required skills for the preschoolers. Appropriate monitoring and regulatory system by the government will enhance efficacy of the initial 5 years foundational stage for children. Time to time training with novel teaching demonstration techniques and implementation of step-by-step module as per the age groups of preschoolers is required to ensure successful preschool education program project.

\section{REFERENCES :}

[1] National Education Policy (2020) Ministry of Human Resource Development, Government of India, Part I: School Education, 7-10. https://www.education.gov.in/sites/upload_files/mhrd/files/ NEP_Final_English_0.pdf

[2] Tierney, L.A., Nelson, A.C., III (2009). Brain Development and the Role of Experience in the Early Years, Zero Three, 30(2), 9-13.

[3] Abankina, I., Filatova, L. (2017). Accessibility of Preschool Education1-23, https://www.researchgate.net/publication/327909981_Accessibility_of_Pre-School_Education.

[4] Early, D. M., Maxwell, K. L., Ponder, B. B., \& Pan, Y. (2017). Improving teacher-child interactions: A randomized control trial of Making the Most of Classroom Interactions and My Teaching Partner professional development models. Early Childhood Research Quarterly, 38(1), 57-70.

[5] Alsobaie, Fahad, M., (2015). Long-Term Impacts of Pre-K Education on Childhood Educational, Social, and Behavioral Development. Journal of Education and Practice, 6(16), 45-49. 
[6] Morgan, H., (2019). Does High-Quality Preschool Benefit Children? What the Research Shows, Educ. Sci. 9(1), 19-28.

[7] Estes, C.D. (2015). Preschool Experience vs. No Preschool Experience: Long Term Effects on Academic and Social Readiness of Children, Graduate Master's Theses, Capstones, and Culminating Projects, 153(1), 1-49.

[8] Mallik, S. (2020) National Education Policy 2020 and Its Comparative Analysis with RTE, American Research Journal of Humanities and Social sciences, 7(1), 1-7.

[9] KPMG, Impact-of-national-education-policy-2020-and-opportunities-for-stakeholders https://assets.kpmg/content/dam/kpmg/in/pdf/2020/08/impact-of-national-education-policy-2020and-opportunities-for-stakeholders.pdf.

[10] Aithal, P. S., Aithal, Shubhrajyotsna (2019). Analysis of Higher Education in Indian National Education Policy Proposal 2019 and its Implementation Challenges. International Journal of Applied Engineering and Management Letters (IJAEML), 3(2), 1-35.

[11] Aithal, P. S., Aithal, Shubhrajyotsna (2020). Analysis of the Indian National Education Policy 2020 towards Achieving its Objectives. International Journal of Management, Technology, and Social Sciences (IJMTS), 5(2), 19-41.

[12] Belsky, J. (2001). Developmental risks (still) associated with early child care. Journal of Child Psychology and Psychiatry and Allied Disciplines, 42(7), 845-859.

[13] Tilak, J. B. G. (2019). Promising but Perplexing Solutions: A Critique of the Draft National Education Policy 2019, 49(4), 686-712.

[14] Maruthavanan, M. (2020). A Study on the Awareness on New Education Policy (2019) among the Secondary School Teachers in Madurai District. International Journal of Education, 8(3), 67-71.

[15] Kalyani, P. (2020). An Empirical Study on NEP 2020 [National Education Policy] with Special Reference to the Future of Indian Education System and Its effects on the Stakeholders. Journal of Management Engineering and Information Technology (JMEIT), 7(5), 1-17.

[16] Pianta, R.C., Barnett, W.S., Burchinal, M., Thornburg, K.R. (2009). The Effects of Preschool Education: What We Know, How Public Policy Is or Is Not Aligned with the Evidence Base, and What We Need to Know, Psychological Science in the Public Interest, 10(2), 49-88.

[17] Devi, L., Cheluvaraju. (2020). A Study on Awareness about the Impact of National Education Policy-2020 Among the Stakeholder of Commerce and Management Disciplinary. European Journal of Business and Management Research, 5(6), 1-5.

[18] Jha, P., Parvati, P. (2020). Long on Rhetoric and Short on substance National Education Policy, 2020. Governance at Banks, 55(34), 14-17.

[19] Sawant, R. G., Sankpal, U. B. (2021). National education policy 2020 and Higher education: a brief review. International Journal of Creative Research Thoughts (IJCRT), 9(1) 3456-3460.

[20] Kaurav, R. P. S., Suresh, K. G., Narula, S. (2020). New education policy: qualitative (contents) analysis and twitter mining (sentiment analysis). Journal of Content, Community \& Communication, 12(6), 4-13.

[21] Manhas, S., Qadiri, F. (2010). A Comparative Study of Preschool Education in Early Childhood Education Centres in India. Contemporary Issues in Early Childhood, 11(4), 443-447.

[22] Gouda, S., Sekher, V.T. (2014). Factors Leading to School Dropouts in India: An Analysis of National Family Health Survey-3 Data. IOSR Journal of Research \& Method in Education (IOSRJRME), 4(6), 75-83.

[23] Desai, M. S., Johnson, R. A. (2014). Integrated systems-oriented student-centric learning environment. Campus-Wide Information Systems, 31(1), 24-45.

[24] Kealey, D. J., Protheroe, D. R., MacDonald, D., Vulpe, T. (2003). Instituting a competency-based training design and evaluation system. Performance Improvement, 42(5), 28-33. 
[25] Aithal, P. S., Kumar, S. (2016). ABC Model of Research Productivity and Higher Educational Institutional Ranking. International Journal of Education and Management Engineering (IJEME), 6(6), 74-84.

[26] Chopra, N. (2012). A study of early childhood education programmes in Delhi, India. International Journal of Early Years Education, 20(2), 159-174.

[27] Gilliam, W.S., Zigler, F.E. (2000). A critical meta-analysis of all evaluations of state funded preschool from 1977 to 1998: Implications for policy, service delivery and program evaluations. Early Childhood Research Quarterly, 15(4), 441-473.

[28] Gorey, K. M. (2001). Early childhood education: A meta-analytic affirmation of the short- and long-term benefits of educational opportunity. School Psychology Quarterly, 16(1), 9-30.

[29] Yizengaw, Y.J., Tessega, M. (2020). The implementation of early childhood care and education (ECCE) in Bahir Dar city administration: A comparative study between private and public preprimary schools. Social Sciences \& Humanities Open, 2(1), 00013.

[30] Manuel, F. M., Gregorio, B. E. (2011). Legal Frameworks for Early Childhood Governance in the Philippines. International Journal of Child Care and Education Policy, 5(1), 65-76.

[31] Gandhi, R. (2020). Effect of lock down during COVID-19 prevention program on migrant labours in India. International Research Journal of Social Science, 9(4), 51-55.

[32] Gandhi, R. (2020). Impact of COVID-19 on Chandigarh-Its causes, consequences and role of community in preventing its transmission. International Journal of Applied Research, 6(4), 308313.

[33] Melhuish, E., Stevens, K.E., Petrogiannis, K., Ariescu, A., Penderi, E., Rentzou, K., Tawell, A., Slot, P., Broekhuizen, M., Leseman, P. (2015). A review of research on the effects of early childhood Education and Care (ECEC) upon child development. CARE project; Curriculum Quality Analysis and Impact Review of European Early Childhood Education and Care (ECEC)1118. Available at http://ecec-care.org/resources/publications/

[34] Saini, M., Singh, M., Kaur, M., Kaur, M. (2021). Analysing the tweets to examine the behavioural response ofIndian citizens over the approval of national education policy 2020. International Journal of Educational Development, 82(1), 102356.

[35] Said, Z., Friesen, H., Al-Ezzah, H. (2014). The importance of practical activities in school science: perspectives of independent school teachers in Qatari schools, Proceedings of EDULEARN14 Conference 7th-9th July 2014, Barcelona, Spain, ISBN: 978-84-617-0557-3, 4847-4856.

[36] Mudzielwana, P. N. (2014). Assessing the Effects of Second Language as a Medium of Instruction in Teaching Preschool Children. International Journal of Educational Sciences, 7(1), 87-98.

[37] Saracho, N. O. (2017). Literacy and language: new developments in research, theory, and practice. Early Child Development and Care, 187(3-4), 299-304.

[38] Nishanthi, R. (2020). Understanding of the Importance of Mother Tongue Learning. International Journal of Trend in Scientific Research and Development (IJTSRD), 5(1), 77-80.

[39] Bachore, M. M. (2014). Learners' Success in Mother Tongue Based Classroom Instruction and the Attitudes and Perceptions of School Communities. International Journal of Sociology of Education, 3(2), 118-135.

[40] Awopetu, V. A. (2016). Impact of Mother Tongue on Children's Learning Abilities in Early Childhood Classroom. Procedia - Social and Behavioral Sciences, 233(1), 58 - 63.

[41] Wyk, J., Mostert, L. M., Hui, F. K. S. (2016). The influence of mother tongue and gender on the acquisition of English (L2). The case of Afrikaans in Windhoek schools, Namibia. Cogent Education, 3(1), 1-12, 1210997. 
[42] Vivas, A., Gelaye, B., Aboset, N., Kumie, A., Berhane, Y., Williams, A.M. (2010). Knowledge, Attitudes, and Practices (KAP) of Hygiene among School Children in Angolela, Ethiopia. J. Prev Med Hyg., 51(2), 73-79.

[43] Leonie, P., Renate, G., Christine, W.V. (2004). Life Skills-Based Hygiene Education: A guidance document on concepts, development and experiences with life skills-based hygiene education in school sanitation and hygiene education programmes. Delft, The Netherlands, IRC International Water and Sanitation Centre, Technical Paper Series; no. 42, 144. https://www.ircwash.org/sites/default/files/Postma-2004-Lifeskills.pdf.

[44] Mousena, E., \& Sidiropoulou, T. (2018). Oral communication skills and pedagogy. New pedagogical challenges in the 21st century, 231-247. IntechOpen Publication.

[45] ALBashtawy, M. (2015). Personal hygiene in school children aged 6-12 years in Jordan. British Journal of School Nursing, 10(8), 395-398.

[46] Lal, S.B., Kavitha, G. (2016). Assessment of Personal Hygiene Knowledge and Practices: An Empirical Study of Schooling Children in Warangal. International Journal of Science and Research (IJSR), 5(8), 1521-1524.

[47] Obeng, S.C. (2008). Personal Cleanliness Activities in Preschool Classrooms. Early Childhood Educational Journal, 36(1), 93-99.

[48] Kerich, C.J., Sang, H., Kipkosgei, A. (2017). Teaching methods used by teachers to facilitate hygienePractices in Early Childhood Education Centers in Londiani Sub-County. International Journal of Scientific and Research Publications, 7(10), 165-171.

[49] Harsismanto, J., Fredrika, L., Wati, N., Padila, Suryani, D., Yandriza (2021). Effectiveness of Playing Origami Intervention on Improvement of Fine Motor Development Pre School Children. Indian Journal of Forensic Medicine \& Toxicology, 15(1), 1107-1112.

[50] Widayati, S., Simatupang, D.N., Sari, P.P. (2020). The Impact of Adduction of Folding Paper Stages for Children's Fine Motor Skills.Advances in Social Science, Education and Humanities Research, 387(1), 62-65.

[51] Herpita, S. (2016). Penerapan Kegiatan Melipat Terhadap Kemampuan Motorik Halus Child Usia 5-6 Tahun Di Tk St. Antonius-2. Jurnal Handayani. 6(1), 99-108.

[52] Aithal, P. S., \& Aithal, Shubhrajyotsna (2020). Implementation Strategies of Higher Education Part of National Education Policy 2020 of India towards Achieving its Objectives. International Journal of Management, Technology, and Social Sciences (IJMTS), 5(2), 283-325. 